\title{
Reliability of Functional Performance and Neurocognitive Tests in Athletes with and without Functional Ankle Instability
}

\author{
Niloofar Mohammadi ${ }^{1}$, Amir Hosein Kahlaee², Mahyar Salavati ${ }^{\star *}$, Behnam Akhbari ${ }^{2}$, Iraj Abdollahi \\ 1. Department of Physiotherapy, School of Rehabilitation, Tehran University of Medical Sciences, Tehran, Iran. \\ 2. Department of Physiotherapy, University of Social Welfare and Rehabilitation Sciences, Tehran, Iran.
}

citation: Mohammadi N, Salavati M, Akhbari B, Kahlaee A.H, Abdollahi I. Reliability of functional performance and neurocognitive tests in athletes with and without functional ankle instability. Physical Therapy. 2015; 5(2):63-72. http://dx.crossref.org/10.15412/J.PTJ.07050201

: https://dx.crossref.org/10.15412/J.PTJ.07050201

Article info:

Received: 05 Feb. 2015

Accepted: 28 May 2015

Keywords:

Functional ankle instability, Star excursion balance test, Hop test, Neurocognitive test, Reliability

\begin{abstract}
A B S T RA C T
Purpose: To assess the reliability of neurocognitive and functional performance tests in athletes with and without functional ankle instability (FAI).

Methods: In this methodological study, 20 athletes with unilateral functional ankle instability (mean age [SD]: 23.40[2.58] y; mean height[SD]: 1.77[0.11] m; mean weight[SD]: 67.00[13.18] $\mathrm{kg}$ ) and 20 uninjured athletes (mean age[SD]: 23.05[2.72] y; mean height: 1.77[0.13] m; mean weight: $66.35[12.21] \mathrm{kg}$ ) matched by sex, sports type and level, age, limb dominance, height, and weight were sampled by convenient method from Karaj volleyball and basketball super league members. Functional performance tests (FPTs) included the star excursion balance test (SEBT), figure-of- 8 , side, square, and single hop tests. Neurocognitive function was assessed with the Deary-Liewald reaction task (DLRT) including simple and choice reaction times and error rate. The intraclass correlation coefficient (ICC) and standard error of measurement (SEM) tests were calculated using SPSS software version 16.
\end{abstract}

Results: There were no statistically significant differences between 2 groups with regard to age $(\mathrm{P}=0.641)$, weight $(\mathrm{P}=0.872)$, height $(\mathrm{P}=0.989)$, and duration of physical activity $(\mathrm{P}=0.94)$. Generally, high to very high level of reliability were determined with ICC ranging from 0.74 to 0.99 , and 0.91 to 0.99 and SEM ranging from 0.03 to 0.69 , and 0.00 to 0.03 for hop tests and SEBT, respectively. Furthermore, ICC values ranged from 0.78 to 0.96 and SEM values from 0.24 to 23.77 for neurocognitive test.

Conclusion: Reliability of the FPTs was found to be high to very high in this study. SEBT seems to be a highly reliable and applicable test to use in clinical and research practice. Although not as reliable as the SEBT, hop test seems also to be a reliable tool to assess the dynamic performance of patients with FAI. The results suggest that DLRT has an acceptable reliability for the measurement of neurocognitive function in patients with FAI.

\footnotetext{
* Corresponding Author:

Mahyar Salavati, $P h D$

Address: Department of Physiotherapy, University of Social Welfare and Rehabilitation Sciences, Tehran, Iran.

Phone: +98 (912) 2979485

E-mail: mahyarsalavati@gmail.com
} 


\section{Introduction}

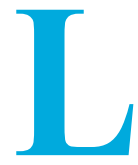

ateral ankle sprains, which are primarily caused by an inversion stress to the joint, account for $60 \%$ of all injuries in athletes $[1,2]$. Functional ankle instability (FAI) is a condition that occurs after an ankle sprain in approximately $40 \%$ of the patients [3]. FAI has been described in many ways, including the "disabling loss of reliable static and dynamic support of a joint" or a "tendency for the foot to give way" [3]. Some researchers have identified functional performance deficits in participants with unstable ankles [2-6], whereas others have not [5-8]. A variety of functional performance tests (FPTs) have been addressed in these patients. Those including frontal plane movements have been found to be sensitive in detecting functional deficits in lateral ankle instability, whereas those solely containing sagittal plane movements did not exhibit performance deficits [6].

Clinicians often use FPTs to evaluate the risk of injury, initial deficits resulting from injury, and improvement after intervention. Dynamic postural control has gained popularity in clinical and research settings as an index of functional performance. The star excursion balance test (SEBT) is one the frequently used tests for dynamic postural control [9]. It measures how far a participant can reach by one foot while keeping balanced on the other foot. Each reaching direction offers unique challenges and requires combinations of sagittal, frontal, and transverse movements and control. The SEBT has shown acceptable sensitivity in screening functional deficits related to chronic ankle instability [10].

Another frequently used FPT to assess lower extremity performance by differentially stressing the joints in sagittal and frontal planes as well as combined rotational stress in the transverse plane is the hop test with all its variations [6]. Some researchers have identified functional performance deficits in participants with unstable ankles during the hop test [2, 4-6] while others have not [5-8]. These tests are helpful because they combine multiple components, such as muscular strength, neuromuscular coordination, and joint stability, which could be affected after joint injury [5].

On the other hand, an injury disrupting joint integrity and or ligamentous sprain, such as FAI, is supposed to impair afferent-efferent pathways. Evidence shows a possible link between brain function and musculoskeletal injury [11-13]. Neurocognitive reaction time appears to be an indicator of elevated risk for lower extremity sprains and strains. The amount of time required for visual perception of a stimulus, information processing, and response to the stimulus may affect an athlete's situational awareness and capability for rapid generation of an appropriate motor response to external perturbations [13]. Thus, quantification of neurocognitive function by a computerized test with standard stimulus presentation, short administration time, and ability to rapidly and accurately analyze and store data which makes comparison with other test performances quite useful to study the main features of FAI $[14,15]$. The Deary-Liewald task (DLRT) is a computerbased neurocognitive task designed to be applied with no specific computer characteristic requirement and with very high internal consistency [16].

To address both the functional and neurocognitive performance of patients with FAI, SEBT, hop, and DLRT tests seem to be useful and informative. Like any other tests, the repeatability of the measurements of these tests in terms of reliability is a major concern which might strongly affect their application. This study aimed to assess the reliability of 2 functional performance and DLRT neurocognitive tests in patients with FAI and subjects with non-ankle sprain

\section{Materials and Methods}

This is a methodological study. The subjects were selected by non-probability convenient sampling method from volleyball and basketball teams attending Karaj professional leagues in 2014. Sample size was calculated from the variance of some dependent variables determined in the pilot phase of the study which yielded 15 cases in each group. To be on the safe side, we enrolled 20 cases in each group.

Twenty athletes with FAI (12 females and 8 males) and 20 subjects without FAI (12 females and 8 males) voluntarily participated in the study. All subjects signed informed consent forms approved by the Ethics Committee of the University of Social Welfare and Rehabilitation Sciences. The non-FAI subjects were matched according to age, weight, height, type and duration of physical activity, and lower-limb dominance with the FAI group. The subjects with FAI had a mean(SD) age, weight, and height of 23.40(2.58) y, 67.00(13.18) kg, and 1.77(0.11) $\mathrm{m}$, respectively. Members of non-FAI group's mean(SD) age, weight, and height were 23.00(2.79) y, 66.35(12.21) $\mathrm{kg}$, and $1.77(0.13) \mathrm{m}$, respectively.

All subjects were college basketball or volleyball players attending the professional league. Both involved and uninvolved limbs were tested in the FAI group. The non- 
FAI group subjects were also tested on both limbs. Their limbs were matched with the FAI group based on the dominancy i.e. the scores of the dominant side of the FAI patients were compared with those of the dominant side of the non-FAI matched subjects. Thus each side of the non-FAI subjects was correspondent to either involved or uninvolved side of the FAI patients which will be named involved-matched and uninvolved-matched limb, respectively. The limb by which subjects preferred to kick a ball, was determined as the dominant one. The screening evaluation was performed by a trained physical therapist through the anterior drawer and talar tilt tests and the mini mental state examination (MMSE) to assess mechanical instability and cognitive function, respectively.

Subjects aged 20-30, would enter the FAI group having met the inclusion criteria: a minimum of one major unilateral inversion sprain resulting in pain, swelling, and function reduction and at least one experience of recurrence of ankle sprain or giving-way or feeling the ankle to be unstable during the previous year. Positive anterior drawer and talar tilt tests indicating mechanical instability and having ankle injury within three months before the study tests would not include the subjects in the FAI group [16].

The exclusion criteria for the non-FAI group were as follows: history of ankle sprain, giving way or feeling of instability in the ankle in the last two years; recent pregnancy, vestibular, respiratory or cognitive disorders (MMSE scores equal or below 23), diabetes, recent injury to the lower extremities or low back or use of medication affecting the cognitive or physical performance [17].

\section{Experimental protocol}

Each participant performed a 5-minute warm-up on a stationary bike at a moderate level of intensity[3]. Tests orders were randomized. The participants were allowed 2 practice trials to get familiarized with FPTs. All functional tests were performed with subjects barefoot [3]. For each of the hop tests, 4 trials were recorded [3], with 30 -second rest periods between trials, and 1 minute of rest between the tests to decrease the chance of fatigue $[3,5]$. Subjects performed 7 trials of the SEBT test in each 8 direction and the last 4 reaches in each direction were recorded. Subjects were given 15 and 30 seconds of rest between trials and directions, respectively [10].

All athletes completed a DLRT computerized neurocognitive test after the familiarization trial. They wore headphones during the test to minimize external distractions. Thirty seconds and 1 minute of rest were implemented between trials and tests, respectively. Par- ticipants performed each test 4 times and the mean score was recorded as the final score for each individual test. The tests were all repeated after 48 to 72 hours interval to assess the inter-session reliability.

\section{Functional tests}

Hop tests

The figure-of- 8 hop test was performed on a 5-m course outlined by cones. The participants were instructed to hop as quickly as possible twice through the course [2, $3,5,6]$ (Figure 1). For the side-hop test, the participants were instructed to hop laterally $30 \mathrm{~cm}$ and back for a total of 10 repetitions [2, 3, 5, 6] (Figure 1). The square hop test was performed on a $40 \times 40 \mathrm{~cm}$ square marked on the floor with tape. Starting outside of the square, the participants were instructed to hop in and out of the square as fast as possible for 5 times. One repetition constituted hopping in and out of the tape outline completely around the square back to the starting point. With the right limb, the participants hopped in a clockwise direction and with the left limb, they hopped in a counterclockwise direction $[3,6]$ (Figure 1). For the single-hop test, the participants were instructed to hop forward as far as possible. The distance was recorded (Figure 1).

If a participant fell, put the contralateral foot down, hopped in the wrong direction or did not complete the trial, it would be discarded and repeated. The time taken to complete each of the figure-of- 8 hop test, side-hop test $[2,5,6]$, and square-hop test [6] was recorded using a hand-held stop-watch. For the single hop test, the distance was recorded from the position of the toes on the starting line to the end of the jump [6].

\section{SEBT}

The SEBTs were performed with the subject standing at the center of a grid placed on the floor, with 8-centimeter scaled lines extending at $45^{\circ}$ increments from the center of the grid. Test performance was recorded in 8 directions: anterolateral (AL), anterior (A), anteromedial $(\mathrm{AM})$, medial $(\mathrm{M})$, posteromedial $(\mathrm{PM})$, posterior $(\mathrm{P})$, posterolateral (PL), and lateral (L).

Subjects were instructed to touch the furthest point on the scaled lines with the reach foot as lightly as possible while keeping their balances, and then return to the bilateral stance. Reach distances were then normalized to the subjects' leg length, which was measured from the anterior superior iliac spine to the distal tip of the medial malleolus [18]. 
The trial would be discarded and repeated if the subject failed to maintain unilateral stance, lifted or moved the stance foot from the grid, touched heavily or came to rest at the touchdown point, made contact with the ground with the reaching foot to maintain balance, or failed to return the reach foot to the starting position [19].

\section{Cognitive test}

DLRT allows the user to conduct simple and 4-choice reaction time procedures. The program is free, easy to use, and needs no special software. Simple reaction time involves reacting to a single stimulus as quickly as possible. Choice reaction time was made complicated by requiring the subject to make the appropriate response to one out of several stimuli. The computerized cognitive assessment was based on the presentation of ' $\mathrm{X}$ ' on a computer monitor.

During the simple reaction time test, a cross would appear in the box on the screen and each time it appeared the athlete was supposed to press the space key as quickly as possible. The test would be repeated 20 times and the reaction time was recorded by the software as the interval between the cross appearance on the screen and the press key event.
In the choice reaction time, there were 4 boxes on the screen. A cross would appear in one of them and the athletes were to press the correct key for that box as quickly as possible. For each box, one specific button on the keyboard was determined as the corresponding key [16].

\section{Statistical analysis}

All data were analyzed by SPSS (version 16). The mean of the 4 trials for each test was used for statistical analysis. Normal distribution was evaluated using the KolmogorovSmirnov test. Relative and absolute reliability were assessed using intra-class correlation coefficient (ICC) and standard error of measurement (SEM), respectively.

\section{Results}

Between groups comparison was done using the independent $t$ test, to compare FAI and control groups. There were no statistically significant differences between the 2 groups with regard to age $(\mathrm{P}=0.641)$, weight $(\mathrm{P}=0.872)$, height $(\mathrm{P}=0.989)$, and duration of physical activity $(\mathrm{P}=0.94)$. The mean values of the functional and neurocognitive variables are listed in Tables 1 and 2, respectively.

Table 1. The mean values of functional and neurocognitive variables.

\begin{tabular}{lccc}
\hline \multirow{2}{*}{ Variables } & & FAI & Non-FAI \\
\cline { 3 - 4 } & & Mean \pm SD & Mean \pm SD \\
\hline \multirow{2}{*}{ Neurocognitive } & SRT(ms) & $330.78 \pm 36.99$ & $294.79 \pm 14.00$ \\
& CRT(ms) & $510.12 \pm 53.55$ & $419.53 \pm 41.88$ \\
& Error & $1.15 \pm 1.01$ & $0.16 \pm 0.31$ \\
\hline
\end{tabular}

\begin{tabular}{|c|c|c|c|c|c|}
\hline \multicolumn{2}{|c|}{ Variables } & \multirow{2}{*}{$\begin{array}{c}\text { Involved limb } \\
13.00 \pm 1.42\end{array}$} & \multirow{2}{*}{$\begin{array}{c}\text { Uninvolved limb } \\
12.92 \pm 1.44\end{array}$} & \multirow{2}{*}{$\begin{array}{c}\begin{array}{c}\text { Involved-matched } \\
\text { limb }\end{array} \\
10.27 \pm 1.11\end{array}$} & \multirow{2}{*}{$\begin{array}{c}\begin{array}{c}\text { Uninvolved-matched } \\
\text { limb }\end{array} \\
10.91 \pm 1.11\end{array}$} \\
\hline \multirow{4}{*}{ Hop tests } & 8-Hop(s) & & & & \\
\hline & Square(s) & $16.10 \pm 1.82$ & $14.32 \pm 1.71$ & $12.23 \pm 1.25$ & $11.63 \pm 1.08$ \\
\hline & Side(s) & $15.94 \pm 1.08$ & $14.18 \pm 1.41$ & $12.40 \pm 1.22$ & $11.66 \pm 1.01$ \\
\hline & Single(m) & $1.92 \pm 0.39$ & $1.94 \pm 0.365$ & $1.95 \pm 0.33$ & $1.95 \pm 0.345$ \\
\hline \multirow{8}{*}{ SEBT } & Ant & $0.96 \pm 0.11$ & $0.94 \pm 0.125$ & $1.005 \pm 0.10$ & $0.95 \pm 0.14$ \\
\hline & AM & $0.995 \pm 0.11$ & $0.97 \pm 0.11$ & $1.03 \pm 0.11$ & $0.98 \pm 0.12$ \\
\hline & Med & $1.03 \pm 0.12$ & $1.01 \pm 0.12$ & $1.07 \pm 0.12$ & $1.045 \pm 0.13$ \\
\hline & PM & $1.05 \pm 0.11$ & $1.03 \pm 0.12$ & $1.11 \pm 0.11$ & $1.08 \pm 0.13$ \\
\hline & Post & $1.05 \pm 0.11$ & $1.07 \pm 0.10$ & $1.12 \pm 0.11$ & $1.12 \pm 0.11$ \\
\hline & PL & $0.905 \pm 0.09$ & $0.96 \pm 0.10$ & $0.98 \pm 0.09$ & $1.02 \pm 0.09$ \\
\hline & Lat & $0.90 \pm 0.075$ & $0.89 \pm 0.10$ & $0.955 \pm 0.084$ & $0.93 \pm 0.084$ \\
\hline & $\mathrm{AL}$ & $0.795 \pm 0.09$ & $0.78 \pm 0.08$ & $0.86 \pm 0.09$ & $0.82 \pm 0.11$ \\
\hline
\end{tabular}

**SRT: Simple Reaction Time.

PHYSICAL TREA † MENTS

**CRT: Choice Reaction Time. 


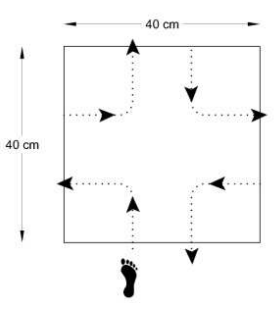

Square hop test

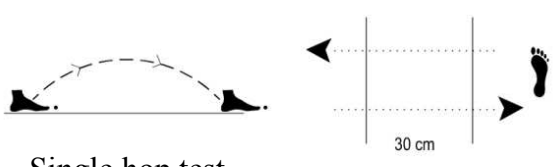

Side hop test

Figure 1. Functional performance tests.

In general, a high to very high level of reliability was determined which were statistically significant $(\mathrm{P}<0.05)$, with ICC ranging from 0.74 to 0.99 and 0.91 to 0.99 and SEM ranging from 0.00 to 0.63 and 0.00 to 0.03 for the hop and SEBT tests, respectively. Also, ICC ranged from 0.78 to 0.98 and SEM from 0.24 to 17.12 for the neurocognitive tests (Tables 3-6).

Intra-session reliability for sessions 1 and 2 of FPTs are reported in Tables 3 and 4, respectively. On the first session, different ICC values of the hop tests ranged

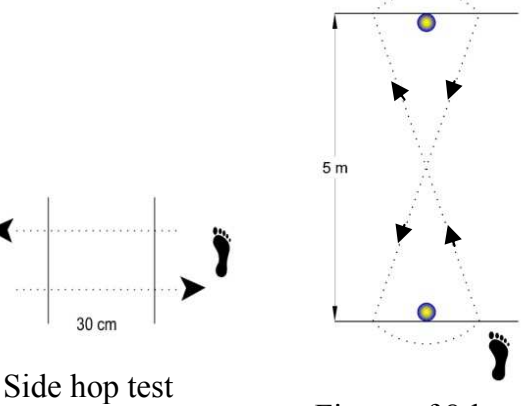

Figure of 8-hop test

PHYSICAL TREA TMENTS

Table 2. Reliability of the first session in FAI and non-FAI group, indicating a very high level of reliability for all tests.

\begin{tabular}{|c|c|c|c|c|c|c|c|c|c|}
\hline & \multirow{3}{*}{ Variables } & \multicolumn{4}{|c|}{ Non-FAl } & \multicolumn{4}{|c|}{ FAI } \\
\hline & & \multicolumn{2}{|c|}{ Uninvolved-matched } & \multicolumn{2}{|c|}{ Involved-matched } & \multicolumn{2}{|c|}{ Uninvolved } & \multicolumn{2}{|l|}{ Involved } \\
\hline & & $\operatorname{ICC}(\mathrm{Cl})^{*}$ & SEM & $\mathrm{ICC}(\mathrm{Cl})$ & SEM & $\mathrm{ICC}(\mathrm{Cl})$ & SEM & $\mathrm{ICC}(\mathrm{Cl})$ & SEM \\
\hline \multirow{4}{*}{$\begin{array}{l}\text { Hop } \\
\text { tests }\end{array}$} & 8-Hop & $\begin{array}{c}0.87(0.772- \\
0.942)\end{array}$ & 0.41 & $\begin{array}{c}0.88(0.781- \\
0.944)\end{array}$ & 0.41 & $\begin{array}{c}0.89(0.797- \\
0.949)\end{array}$ & 0.50 & $0.93(0.871-0.969)$ & 0.39 \\
\hline & Square & $\begin{array}{c}0.83(0.696- \\
0.918)\end{array}$ & 0.48 & $\begin{array}{c}0.91(0.833- \\
0.959)\end{array}$ & 0.39 & $\begin{array}{c}0.90(0.812- \\
0.953)\end{array}$ & 0.57 & $0.86(0.798-0.949)$ & 0.63 \\
\hline & Side & $\begin{array}{c}0.74(0.564- \\
0.870)\end{array}$ & 0.58 & $\begin{array}{c}0.85(0.726- \\
0.927)\end{array}$ & 0.47 & $\begin{array}{c}0.87(0.763- \\
0.939)\end{array}$ & 0.54 & $0.78(0.624-0.893)$ & 0.56 \\
\hline & Single & $\begin{array}{c}0.99(0.980- \\
0.996)\end{array}$ & 0.03 & $\begin{array}{c}0.98(0.964- \\
0.992)\end{array}$ & 0.05 & $\begin{array}{c}0.98(0.968- \\
0.993)\end{array}$ & 0.05 & $0.98(0.962-0.991)$ & 0.05 \\
\hline \multirow{8}{*}{ SEBT } & Ant & $\begin{array}{c}0.98(0.957- \\
0.990)\end{array}$ & 0.00 & $\begin{array}{c}0.94(0.881- \\
0.972)\end{array}$ & 0.03 & $\begin{array}{c}0.98(0.953- \\
0.989)\end{array}$ & 0.00 & $0.95(0.912-0.979)$ & 0.03 \\
\hline & AM & $\begin{array}{c}0.98(0.956- \\
0.990)\end{array}$ & 0.00 & $\begin{array}{c}0.96(0.924- \\
0.982)\end{array}$ & 0.03 & $\begin{array}{c}0.97(0.936- \\
0.985)\end{array}$ & 0.00 & $0.96(0.932-0.984)$ & 0.00 \\
\hline & Med & $\begin{array}{c}0.98(0.953- \\
0.989)\end{array}$ & 0.00 & $\begin{array}{c}0.97(0.937- \\
0.985)\end{array}$ & 0.00 & $\begin{array}{c}0.97(0.949- \\
0.988)\end{array}$ & 0.00 & $0.97(0.940-0.986)$ & 0.00 \\
\hline & PM & $\begin{array}{c}0.97(0.946- \\
0.988)\end{array}$ & 0.00 & $\begin{array}{c}0.96(0.916- \\
0.980)\end{array}$ & 0.03 & $\begin{array}{c}0.97(0.943- \\
0.987)\end{array}$ & 0.00 & $0.96(0.930-0.984)$ & 0.00 \\
\hline & Post & $\begin{array}{c}0.97(0.936- \\
0.985)\end{array}$ & 0.00 & $\begin{array}{c}0.95(0.904- \\
0.977)\end{array}$ & 0.03 & $\begin{array}{c}0.95(0.911- \\
0.979)\end{array}$ & 0.03 & $0.95(0.898-0.976)$ & 0.03 \\
\hline & PL & $\begin{array}{c}0.95(0.904- \\
0.978)\end{array}$ & 0.00 & $\begin{array}{c}0.93(0.875- \\
0.970)\end{array}$ & 0.03 & $\begin{array}{c}0.96(0.923- \\
0.982)\end{array}$ & 0.00 & $0.91(0.827-0.957)$ & 0.03 \\
\hline & Lat & $\begin{array}{c}0.96(0.930- \\
0.984)\end{array}$ & 0.00 & $\begin{array}{c}0.92(0.959- \\
0.991)\end{array}$ & 0.03 & $\begin{array}{c}0.92(0.887- \\
0.973)\end{array}$ & 0.00 & $0.92(0.958-0.991)$ & 0.00 \\
\hline & $\mathrm{AL}$ & $\begin{array}{c}0.97(0.949- \\
0.988)\end{array}$ & 0.00 & $\begin{array}{c}0.93(0.859- \\
0.966)\end{array}$ & 0.03 & $\begin{array}{c}0.94(0.885- \\
0.973)\end{array}$ & 0.00 & $0.92(0.850-0.963)$ & 0.03 \\
\hline
\end{tabular}


Table 3. Reliability of the second session in FAI and non-FAI group, showing a high to very high level of reliability for all tests.

\begin{tabular}{|c|c|c|c|c|c|c|c|c|c|}
\hline & & \multicolumn{4}{|c|}{ Non-FAl } & \multicolumn{4}{|c|}{ FAI } \\
\hline \multicolumn{2}{|c|}{ variables } & \multicolumn{2}{|c|}{ Uninvolved-matched } & \multicolumn{2}{|c|}{ Involved-matched } & \multicolumn{2}{|c|}{ Uninvolved } & \multicolumn{2}{|l|}{ Involved } \\
\hline & & $\operatorname{ICC}(\mathrm{Cl})^{*}$ & SEM & $\mathrm{ICC}(\mathrm{Cl})$ & SEM & ICC(CI) & SEM & ICC(CI) & SEM \\
\hline \multirow{4}{*}{ HOP tests } & 8-Hop & $\begin{array}{c}0.88(0.779- \\
0.944)\end{array}$ & 0.40 & $\begin{array}{c}0.87(0.761- \\
0.938)\end{array}$ & 0.40 & $0.95(0.902-0.977)$ & 0.34 & 0.94(0.884-0.972) & 0.35 \\
\hline & Square & $\begin{array}{c}0.86(0.745- \\
0.934)\end{array}$ & 0.42 & $\begin{array}{c}0.94(0.882- \\
0.972)\end{array}$ & 0.32 & $0.95(0.904-0.977)$ & 0.41 & 0.95(0.910-0.979) & 0.39 \\
\hline & Side & $\begin{array}{c}0.87(0.757- \\
0.937)\end{array}$ & 0.44 & $\begin{array}{c}0.89(0.802- \\
0.950)\end{array}$ & 0.40 & $0.92(0.843-0.962)$ & 0.46 & $0.89(0.798-0.949)$ & 0.41 \\
\hline & Single & $\begin{array}{c}0.99(0.972- \\
0.994)\end{array}$ & 0.04 & $\begin{array}{c}0.99(0.975- \\
0.994)\end{array}$ & 0.04 & 0.98(0.969-0.993) & 0.05 & 0.98(0.969-0.993) & 0.05 \\
\hline \multirow{8}{*}{ SEBT } & Ant & $\begin{array}{c}0.98(0.965- \\
0.992)\end{array}$ & 0.00 & $\begin{array}{c}0.97(0.950- \\
0.989)\end{array}$ & 0.00 & $0.98(0.962-0.991)$ & 0.00 & 0.97(0.949-0.988) & 0.00 \\
\hline & AM & $\begin{array}{c}0.98(0.967- \\
0.992)\end{array}$ & 0.00 & $\begin{array}{c}0.97(0.941- \\
0.986)\end{array}$ & 0.00 & $0.97(0.941-0.986)$ & 0.00 & 0.96(0.931-0.984) & 0.00 \\
\hline & Med & $\begin{array}{c}0.98(0.958- \\
0.990)\end{array}$ & 0.00 & $\begin{array}{c}0.97(0.947- \\
0.988)\end{array}$ & 0.00 & $0.97(0.951-0.989)$ & 0.00 & 0.97(0.951-0.989) & 0.00 \\
\hline & PM & $\begin{array}{c}0.98(0.954- \\
0.990)\end{array}$ & 0.00 & $\begin{array}{c}0.97(0.942- \\
0.987)\end{array}$ & 0.00 & $0.97(0.945-0.987)$ & 0.00 & 0.97(0.939-0.986) & 0.00 \\
\hline & Post & $\begin{array}{c}0.97(0.944- \\
0.987)\end{array}$ & 0.00 & $\begin{array}{c}0.95(0.898- \\
0.976)\end{array}$ & 0.03 & $0.97(0.935-0.985)$ & 0.00 & $0.96(0.932-0.984)$ & 0.00 \\
\hline & $\mathrm{PL}$ & $\begin{array}{c}0.96(0.921- \\
0.982)\end{array}$ & 0.00 & $\begin{array}{c}0.92(0.895- \\
0.966)\end{array}$ & 0.03 & $0.96(0.929-0.984)$ & 0.00 & $0.92(0.858-0.966)$ & 0.03 \\
\hline & Lat & $\begin{array}{c}0.98(0.954- \\
0.989)\end{array}$ & 0.00 & $\begin{array}{c}0.96(0.926- \\
0.983)\end{array}$ & 0.00 & $0.95(0.897-0.976)$ & 0.00 & 0.95(0.898-0.976) & 0.00 \\
\hline & AL & $\begin{array}{l}0.97(0.948- \\
0.988)\end{array}$ & 0.00 & $\begin{array}{l}0.96(0.925- \\
0.983)\end{array}$ & 0.00 & $0.94(0.894-0.975)$ & 0.00 & 0.95(0.896-0.976) & 0.00 \\
\hline
\end{tabular}

${ }^{*}$ CI: Confidence Interval.

PHYSICAL TREA TMENTS

values were $0.96-0.98,0.92-0.97,0.94-0.98$, and $0.92-$ 0.97 on the second session while SEM ranged from 0.00 to 0.03 on both sessions. Inter-session reliabilities of the functional tests are shown in Table 5. For the hop tests, ICC ranges were 0.96-0.99, 0.94-0.99, 0.98-0.99 and 0.94-0.99 while SEM ranges were 0.04-0.30, 0.03$0.43,0.03-0.30$, and $0.00-0.37$ in uninvolved-matched, involved-matched, uninvolved, and involved limbs, respectively. Regarding the SEBT tests, total range of ICC and SEM values were $0.94-0.99$ and $0.00-0.03$ for all limbs, respectively. The mean differences of the involved and involved-matched scores of the functional tests of the first session are reported in Table 5.

Table 6 illustrates the intra-session and inter-session reliability of the neurocognitive tests in both groups. Intra-session reliability of the first and second sessions of the neurocognitive tests (including SRT, CRT, and error rate) ranged as $0.78-0.94$ for both groups while SEM score ranges were $0.83-17.12$ and $0.24-10.37$ for the FAI and the non-FAI groups, respectively. ICC values indicating inter-session reliability of the neurocognitive tests ranged as $0.85-0.98$ for both groups while SEM values were between $0.51-11.08,0.39-12.43$ in the FAI and the non-FAI groups, respectively.

\section{Discussion}

The purpose of the study was to determine the reliability of functional performance and neurocognitive tests in athletes with and without FAI. We administered functional tests to evaluate the functional consequences of FAI by stressing the ankle joint in multiple planes.

\section{Functional tests}

Robinson and Gribble reported maximum normalized excursion distance scores of the SEBT to get stabilized after 4 practice trials [18]. We therefore used the same number of trials instead of the previously suggested 6 trials [19] to assess the reach distance. The inter-session and intra-session reliability of the SEBT were assessed by comparing the mean values of 4 trials for each session and computing the correlation of the 4 trials of the first session, respectively. We found that the inter-and intra-session reliabilities of SEBT scores in all directions 
Table 4. Inter-session reliability in FAI and non-FAI group, indicating a very high level of reliability for all tests.

\begin{tabular}{|c|c|c|c|c|c|c|c|c|c|c|}
\hline \multirow{3}{*}{\multicolumn{2}{|c|}{ Variables }} & \multicolumn{4}{|c|}{ Non-FAI } & \multicolumn{4}{|c|}{ FAI } & \multirow{3}{*}{$\begin{array}{l}\text { Involved-involved } \\
\text { matched mean } \\
\text { difference }\end{array}$} \\
\hline & & \multicolumn{2}{|c|}{ Uninvolved-matched } & \multicolumn{2}{|c|}{ Involved-matched } & \multicolumn{2}{|c|}{ Uninvolved } & \multicolumn{2}{|c|}{ Involved } & \\
\hline & & $\mathrm{ICC}(\mathrm{Cl})^{*}$ & SEM & $\mathrm{ICC}(\mathrm{Cl})$ & SEM & $\mathrm{ICC}(\mathrm{Cl})$ & SEM & $\mathrm{ICC}(\mathrm{Cl})$ & SEM & \\
\hline \multirow{4}{*}{ HOP } & 8-Hop & $\begin{array}{c}0.96(0.904- \\
0.985)\end{array}$ & 0.30 & $\begin{array}{c}0.97(0.915- \\
0.987)\end{array}$ & 0.28 & $\begin{array}{c}0.98(0.953- \\
0.993)\end{array}$ & 0.28 & $\begin{array}{c}0.98(0.943- \\
0.991)\end{array}$ & 0.29 & -2.73 \\
\hline & Square & $\begin{array}{c}0.96(0.895- \\
0.984)\end{array}$ & 0.30 & $\begin{array}{c}0.94(0.838- \\
0.975)\end{array}$ & 0.43 & $\begin{array}{c}0.99(0.968- \\
0.995)\end{array}$ & 0.28 & $\begin{array}{c}0.98(0.970- \\
0.995)\end{array}$ & 0.28 & -3.81 \\
\hline & Side & $\begin{array}{c}0.97(0.929- \\
0.989)\end{array}$ & 0.25 & $\begin{array}{c}0.96(0.900- \\
0.984)\end{array}$ & 0.32 & $\begin{array}{c}0.98(0.945- \\
0.991)\end{array}$ & 0.30 & $\begin{array}{c}0.94(0.854- \\
0.979)\end{array}$ & 0.37 & -3.54 \\
\hline & Single & $\begin{array}{c}0.99(0.979- \\
0.997)\end{array}$ & 0.04 & $\begin{array}{c}0.99(0.986- \\
0.998)\end{array}$ & 0.03 & $\begin{array}{c}0.99(0.993- \\
0.999)\end{array}$ & 0.03 & $\begin{array}{c}0.99(0.998- \\
1.000)\end{array}$ & 0.00 & 0.03 \\
\hline \multirow{8}{*}{ SEBT } & Ant & $\begin{array}{c}0.99(0.994- \\
0.999)\end{array}$ & 0.00 & $\begin{array}{c}0.99(0.979- \\
0.997)\end{array}$ & 0.00 & $\begin{array}{c}0.99(0.991- \\
0.999)\end{array}$ & 0.00 & $\begin{array}{c}0.99(0.975- \\
0.996)\end{array}$ & 0.00 & 0.04 \\
\hline & AM & $\begin{array}{c}0.99(0.980- \\
0.997)\end{array}$ & 0.00 & $\begin{array}{c}0.99(0.972- \\
0.996)\end{array}$ & 0.00 & $\begin{array}{c}0.99(0.974- \\
0.996)\end{array}$ & 0.00 & $\begin{array}{c}0.99(0.976- \\
0.996)\end{array}$ & 0.00 & 0.04 \\
\hline & Med & $\begin{array}{c}0.99(0.967- \\
0.995)\end{array}$ & 0.00 & $\begin{array}{c}0.99(0.964- \\
0.994)\end{array}$ & 0.00 & $\begin{array}{c}0.98(0.959- \\
0.994)\end{array}$ & 0.00 & $\begin{array}{c}0.99(0.972- \\
0.996)\end{array}$ & 0.00 & 0.03 \\
\hline & PM & $\begin{array}{c}0.99(0.983- \\
0.997)\end{array}$ & 0.00 & $\begin{array}{c}0.98(0.943- \\
0.991)\end{array}$ & 0.03 & $\begin{array}{c}0.99(0.987- \\
0.998)\end{array}$ & 0.00 & $\begin{array}{c}0.98(0.946- \\
0.991)\end{array}$ & 0.00 & 0.06 \\
\hline & Post & $\begin{array}{c}0.99(0.988- \\
0.998)\end{array}$ & 0.00 & $\begin{array}{c}0.98(0.942- \\
0.991)\end{array}$ & 0.03 & $\begin{array}{c}0.99(0.986- \\
0.998)\end{array}$ & 0.00 & $\begin{array}{c}0.98(0.961- \\
0.994)\end{array}$ & 0.00 & 0.07 \\
\hline & PL & $\begin{array}{c}0.99(0.983- \\
0.997)\end{array}$ & 0.00 & $\begin{array}{c}0.96(0.910- \\
0.986)\end{array}$ & 0.03 & $\begin{array}{c}0.99(0.985- \\
0.998)\end{array}$ & 0.00 & $\begin{array}{c}0.98(0.937- \\
0.990)\end{array}$ & 0.00 & 0.08 \\
\hline & Lat & $\begin{array}{c}0.94(0.835- \\
0.974)\end{array}$ & 0.03 & $\begin{array}{c}0.99(0.989- \\
0.998)\end{array}$ & 0.00 & $\begin{array}{c}0.99(0.984- \\
0.998)\end{array}$ & 0.00 & $\begin{array}{c}0.99(0.983- \\
0.997)\end{array}$ & 0.00 & 0.06 \\
\hline & $\mathrm{AL}$ & $\begin{array}{c}0.99(0.885- \\
0.998)\end{array}$ & 0.00 & $\begin{array}{c}0.97(0.928- \\
0.989)\end{array}$ & 0.00 & $\begin{array}{c}0.99(0.980- \\
0.997)\end{array}$ & 0.00 & $\begin{array}{c}0.96(0.893- \\
0.983)\end{array}$ & 0.03 & 0.07 \\
\hline
\end{tabular}

${ }^{*} \mathrm{CI}$ : Confidence Interval.

PHYSICAL TREA T MENTS

in both limbs of the subjects in both groups were very high. The scores of the SEBT in our study were found to be more reliable than the previous results of Hertel et al. [20] and Plisky et al. [21] (very high vs. high). Hertel et al. [20] investigated the patients with chronic ankle instability, including mechanical instabilities while Plisky et al. [21] studied non-injured basketball players. In Hertel et al. study a significant learning effect was found on day 1, where trials 4-6 had significantly higher reach scores than trials 1-3 [20]. This led Hertel et al. to recommend a protocol which included 6 practice trials prior to 3 measured trials to ensure that the learning effect would not affect performance [20]. The intrasession reliability scores in our study were not different between the 2 sessions because the ICC confidence intervals had considerable overlapping. Two other sources of differences between the results of our study and those of Hertel et al. are related to first our subjects who were

Table 5. Reliability of neurocognitive test in FAI and non-FAI group, showing a high to very high level of reliability for all tests.

\begin{tabular}{|c|c|c|c|c|c|c|c|c|c|c|c|c|}
\hline \multirow{3}{*}{ Variables } & \multicolumn{4}{|c|}{ First session } & \multicolumn{4}{|c|}{ Second session } & \multicolumn{4}{|c|}{ Inter-session } \\
\hline & \multicolumn{2}{|c|}{ Non-FAI } & \multicolumn{2}{|l|}{ FAI } & \multicolumn{2}{|c|}{ Non-FAl } & \multicolumn{2}{|c|}{ FAI } & \multicolumn{2}{|c|}{ Non-FAl } & \multicolumn{2}{|l|}{ FAI } \\
\hline & $\operatorname{ICC}(\mathrm{CI}) *$ & SEM & $\mathrm{ICC}(\mathrm{Cl})$ & SEM & $\mathrm{ICC}(\mathrm{Cl})$ & SEM & $\operatorname{ICC}(\mathrm{Cl})$ & SEM & $\mathrm{ICC}(\mathrm{Cl})$ & SEM & $\mathrm{ICC}(\mathrm{Cl})$ & SEM \\
\hline SRT & $\begin{array}{c}0.79(0.642 \\
-0.899)\end{array}$ & 6.97 & $\begin{array}{c}0.94(0.881- \\
0.972)\end{array}$ & 9.52 & $\begin{array}{c}0.84(0.717- \\
0.925)\end{array}$ & 5.62 & $\begin{array}{c}0.79(0.640- \\
0.899)\end{array}$ & 17.12 & $\begin{array}{c}0.86(0.653- \\
0.946)\end{array}$ & 6.68 & $\begin{array}{c}0.96(0.903- \\
0.985)\end{array}$ & 9.70 \\
\hline CRT & $\begin{array}{c}0.94(0.889- \\
0.974)\end{array}$ & 10.37 & $\begin{array}{c}0.92(0.847- \\
0.963)\end{array}$ & 15.84 & $\begin{array}{c}0.94(0.878- \\
0.971)\end{array}$ & 9.40 & $\begin{array}{c}0.94(0.882- \\
0.972)\end{array}$ & 14.29 & $\begin{array}{c}0.95(0.865- \\
0.979)\end{array}$ & 12.43 & $\begin{array}{c}0.98(0.947- \\
0.992)\end{array}$ & 11.08 \\
\hline Error rate & $\begin{array}{c}0.85(0.703- \\
0.934)\end{array}$ & 0.24 & $\begin{array}{c}0.78(0.564- \\
0.903)\end{array}$ & 0.95 & $\begin{array}{c}0.88(0.757- \\
0.946)\end{array}$ & 0.34 & $\begin{array}{c}0.81(0.629- \\
0.917)\end{array}$ & 0.83 & $\begin{array}{c}0.96(0.642- \\
1.285)\end{array}$ & 0.39 & $\begin{array}{c}0.85(0.620- \\
0.940)\end{array}$ & 0.51 \\
\hline
\end{tabular}

${ }^{*} \mathrm{CI}$ : Confidence Interval.

**SRT: Simple Reaction Time.

**CRT: Choice Reaction Time. 
barefoot while performing the tests and second using normalized data for analysis while Hertel et al. did not [20]. Like our results, SEBT scores in Plisky et al. [21] study (with normalized scores) were found to be very high. This might show that having a 3-trial practice prior to testing, makes 4 trials as reliable as the 6-trial testing condition. The intra-session reliability for the SEBT tests in healthy adults was found to be as low as "moderate to high" in Kinzey and Armstrong study which made the authors recommend several practice trials before the main tests. Subjects in this study were not allowed to touch down with the foot at the point of maximum reach and the examiner had to estimate a point on the floor corresponding to maximum reach distance. This may have influenced the ICC values [22].

Reliability of the hop tests was found to be high to very high in this study. Among the different variations of the test, side-hop was the least reliable one in both limbs of the both groups. This finding is compatible with those of Caffrey and Bolgla [2, 23]. The lower reliability of the side-hop test in comparison with other aspects of this test cannot simply be attributed to frontal plane stresses on the joint in the test which are in the injury plane because the situation was the same in the uninvolved side and even in non-FAI subjects. Further studies with more precise controlled and manipulation of the conditions are needed to explain why the side-hop test shows lower reliability than the other hop tests. However, although not as reliable as the SEBT test, hop test stressing the ankle joint in multiple planes seems to be a reliable tool to assess the dynamic performance of the patients with FAI.

\section{The neurocognitive test}

The literature suggests that neurocognitive characteristics can play an important role in coordination, sports performance, and injury [24]. Physical activity requires situational awareness of a broad attentional field to continuously monitor the surrounding environment, filter irrelevant information, and simultaneously execute complex motor programs [25-27]. Little is known about the reliability of DLRT in athletes. The results of this study indicate that the test is highly to very highly reliable within and between sessions when administered to athletes with and without FAI. Thus, DLRT seems to be a useful and applicable tool when neurocognition quantification in these athletes is the concern. The DLRT had been previously found to yield reliable and valid measures in healthy populations [16]. It allows the user to conduct simple and 4-choice reaction time procedures. The program is free, easy to use, needs no special software, and provides enough flexibility for coping the different needs of various populations while keeping the comparability characteristic because of the same basic task [16]. The findings of our study suggest that DLRT is a reliable tool for the measurement of neurocognitive function.

The use of clinical diagnostic testing depends on the reliability and validity of the testing procedure. The purpose of this study was to investigate the reliability of functional performance and neurocognitive tests. We believe that FPTs provide a reliable measure of lower extremity performance in athletes with and without FAI, when following a standardized protocol. The DLRT is designed to run on all laptop and desktop computers, such that it needs no specific requirements for the computers they are ran on. Based on the observations of the present study, we concluded that DLRT is a reliable tool for measuring neurocognitive function (including SRT, CRT, and error rate).

\section{Acknowledgements}

We appreciate the financial support of University of Social Welfare and Rehabilitation Sciences.

\section{Conflict of Interests}

The authors declared no conflict of interests.

\section{References}

[1] Akbari M, Karimi H, Farahini H, Faghihzadeh S. Balance problems after unilateral lateral ankle sprains. Journal of Rehabilitation Research \& Development. 2006; 43(7):819-24.

[2] Caffrey E, Docherty CL, Schrader J, Klossner J. The ability of 4 single-limb hopping tests to detect functional performance deficits in individuals with functional ankle instability. Journal of Orthopaedic and Sports Physical Therapy. 2009; 39(11):799-806. doi: 10.2519/jospt.2009.3042

[3] Buchanan AS, Docherty CL, Schrader J. Functional performance testing in participants with functional ankle instability and in a healthy non-FAI group. Journal of Athletic Training. 2008; 43(4):342-46. doi: 10.4085/1062-6050-43.4.342

[4] Jerosch J, Bischof M. Proprioceptive capabilities of the ankle in stable and unstable joints. Sports \& Exercise Injury. 1996; 2:167-71.

[5] Docherty CL, Arnold BL, Gansneder BM. Functional-performance deficits in volunteers with functional ankle instability. Journal of Athletic Training. 2005; 40(1):30-34.

[6] Sharma N, Sharma A, Sandhu JS. Functional performance testing in athletes with functional ankle instability. Asian Journal of Sports Medicine. 2011; 2(4):249-58. 
[7] Worrell TW, Booher LD, Hench KM. Closed kinetic chain assessment following inversion ankle sprain. Journal of Scientific Reports. 2010;3(3):197-203.

[8] Munn J, Beard DJ, Refshauge KM, Lee RW. Do functionalperformance tests detect impairment in subjects with ankle instability? Journal of Sport Rehabilitation. 2002; 11(1):40-50.

[9] Gribble PA, Kelly SE, Refshauge KM, Hiller CE. Interrater reliability of the Star Excursion Balance Test. Journal of Athletic Training; 2013; 48(5):621-26.

[10] Olmsted LC, Carcia CR, Hertel J, Shultz SJ. Efficacy of the Star Excursion Balance Tests in detecting reach deficits in subjects with chronic ankle instability. Journal of Athletic Training. 2002; 37(4):501-06.

[11] Hutchison M, Comper P, Mainwaring L, Richards D. The influence of musculoskeletal injury on cognition implications for concussion research. American Journal of Sports Medicine. 2011; 39(11):2331-337.

[12] Swanik CB, Covassin T, Stearne DJ, Schatz P. The relationship between neurocognitive function and noncontact anterior cruciate ligament injuries. American Journal of Sports Medicine. 2007; 35(6):943-48.

[13] Wilkerson GB. Neurocognitive reaction time predicts lower extremity sprains and strains. Journal of Athletic Training. 2012; 17(6):4-9.

[14] McCrory P, Makdissi M, Davis G, Collie A. Value of neuropsychological testing after head injuries in football. British Journal of Sports Medicine. 2005; 39(Suppl 1):i58-i63.

[15] Lovell M. The management of sports-related concussion: current status and future trends. Clinics in Sports Medicine. 2009; 28(1):95-111.

[16] Deary IJ, Liewald D, Nissan J. A free, easy-to-use, computer-based simple and four-choice reaction time programme: the Deary-Liewald reaction time task. Behaviour Research Methods. 2011; 43(1):258-68.

[17] Rahnama L, Salavati M, Akhbari B, Mazaheri M. Attentional demands and postural control in athletes with and without functional ankle instability. Journal of Orthopaedic \& Sports Physical Therapy. 2010; 40(3):180-87.

[18] Robinson RH, Gribble PA. Support for a reduction in the number of trials needed for the Star Excursion Balance Test. Archives of Physical Medicine and Rehabilitation. 2008; 89(2):364-70.

[19] Hertel J, Braham RA, Hale SA, Olmsted LC. Simplifying the star excursion balance test: analyses of subjects with and without chronic ankle instability. Journal of Orthopaedic and Sports Physical Therapy. 2006; 36(3):131-37.

[20] Hertel J, Miller SJ, Denegar CR. Intratester and intertesterreliability during the Star Excursion Balance Test. Journal of Sport Rehabilitation. 2000; 9(2):104-16.

[21] Plisky PJ, Rauh MJ, Kaminski TW, Underwood FB. Star Excursion Balance Test as a predictor of lower extremity injury in high school basketball players. Journal of Orthopaedic \& Sports Physical Therapy. 2006; 36(12):911-19.

[22] Kinzey SJ, Armstrong CW. The reliability of the star-excursion test in assessing dynamic balance. Journal of Orthopaedic \& Sports Physical Therapy. 1998; 27(5):356-60.
[23] Bolgla LA, Keskula DR. Reliability of lower extremity functional performance tests. Journal of Orthopaedic \& Sports Physical Therapy. 1997; 26(3):138-42.

[24] Iverson GL, Lovell MR, Collins MW. Interpreting change on ImPACT following sport concussion. Clinical Neuropsychology. 2003; 17(4):460-67.

[25] Landers DM, Qi WM, Courtet P. Peripheral narrowing among experienced and inexperienced rifle shooters under low-and high-stress conditions. Research Quarterly for Exercise and Sport. 1985; 56(2):122-30.

[26] Nideffer RM. Comparison of self-report and performance measures of attention: a second look. Perceptual and Motor Skills. 1977; 45(3):1291-294.

[27] Weinberg R, Hunt V. Effects of structural integration on state-trait anxiety. Journal of Clinical Psychology. 1979; 35(2):319-22. 
